Article

\title{
Saddle Position-Based Method for Extraction of Depressions in Fengcong Areas by Using Digital Elevation Models
}

\author{
Xianwu Yang ${ }^{1,2,3}$ (D), Guoan Tang ${ }^{1,3,4}$, Xin Meng ${ }^{1,3}$ and Liyang Xiong $1,3,4, *$ (D) \\ 1 Key laboratory of Virtual Geographic Environment, Ministry of Education, Nanjing Normal University, \\ Nanjing 210023, China; xianwu82@163.com (X.Y.); tangguoan@njnu.edu.cn (G.T.); \\ xinmeng94@126.com (X.M.) \\ 2 School of Geographic Sciences, Xinyang Normal University, Xinyang 464000, China \\ 3 Jiangsu Center for Collaborative Innovation in Geographical Information Resource Development and \\ Application, Nanjing 210023, China \\ 4 State Key Laboratory Cultivation Base of Geographical Environment Evolution (Jiangsu Province), \\ Nanjing 210023, China \\ * $\quad$ Correspondence: xiongliyang@163.com; Tel.: +86-152-5187-4227
}

Received: 7 March 2018; Accepted: 26 March 2018; Published: 1 April 2018

\begin{abstract}
A karst depression is an important sign of the development stage of karst landforms. The morphological characteristics of depressions can help reflect the development and evolution process of such landforms. The accurate identification and extraction of depressions in Fengcong areas are the basis of this research on karst depressions. Previous studies on Fengcong depressions were primarily based on manual surveys, remote sensing image interpretation, and manual map plotting or GIS-based techniques. The extracted landform units of Fengcong depressions in these studies were not accurate and even inauthentic in certain cases. Thus, this work proposes a method for extracting Fengcong depressions in karst areas which is based on terrain saddle points and uses digital elevation models (DEMs). First, the surface morphology of the Fengcong karst area is analyzed. Second, saddles are detected from the intersection points, and spatial trend surfaces are generated by interpolating the elevations of these saddle points. The interface between pinnacles and depressions can be determined by the trend surface. We applied the method in a case Fengcong area of the Lijiang River in Guilin, China. Results showed that the proposed method successfully divided the positive terrain form of pinnacles and the negative terrain form of the depressions in the Fengcong karst area. A total of 188 surface depressions were extracted, whose average area was $0.14 \mathrm{~km}^{2}$ and polygonal depression density was $2.5 \mathrm{~km}^{2}$. Results also showed that most of the depressions were stable in terms of the morphological features of area and depth. A total of $94 \%$ of the depth measured less than $60 \mathrm{~m}$, and the area was less than $0.5 \mathrm{~km}^{2}$. This proposed method can accurately determine the boundary of depressions and provide an important reference for quantitative research on the Fengcong depression terrain in karst landforms.
\end{abstract}

Keywords: Fengcong depression; saddle; karst; DEMs

\section{Introduction}

A karst topography is a landscape formed from the dissolution of soluble rocks, such as limestone, dolomite, and gypsum. The karst Fengcong area (also known as cockpit karst and peak cluster) is characterized by roughly conical hills separated by deep closed depressions, all standing on a common bedrock base forming a continuous terrain of steep slopes and significant relief [1]. It is also known as Fengcong depression. The Fengcong depression is the most typical form, and the most 
noticeable feature of karst surface morphology is an indication of developed karst land [2]. Fengcong depressions are the key factor in studying karst hydrological models and evolution. The accurate division and quantitative identification of Fengcong depressions are scientifically important in the study of karst landforms. A Fengcong depression comprises clustered peaks that share a common base with deep depressions [3-7]. The key and basic problem in the study of Fengcong depressions is determining the boundaries or spatial interfaces of karst depressions. The typical karst surface form of Fengcong depression areas has prompted many studies, especially on the classification, morphological characteristics, and hazard evaluation of such depressions [8-19]. Existing research presents two main views in the extraction of Fengcong depressions.

First, a Fengcong depression is defined as an entire range surrounded by a watershed. In the study of such depressions, most researchers regard the entire range that is surrounded by peaks as a depression (Figure 1a). The top of the mountain is extracted and then connected to construct a polygon, which is considered an extracted Fengcong karst depression. This method is simple and easy to implement and thus considerably simplifies the division of depressions and statistical analysis. Therefore, this technique has been adopted in many studies [20-22]. However, this understanding of depressions gives an impression that an entire Fengcong depression area should be negative terrain $[1,23,24]$. This assumption contradicts the theory that Fengcong is a combination of positive and negative terrains [3,25-28]. In addition, a Fengcong depression is always related to adjacent depressions; this relation is inconsistent with the concept of geomorphological depressions [3,6,29]. Therefore, the extracted Fengcong depressions by using above method should be inappropriate from the perspective of geomorphology.

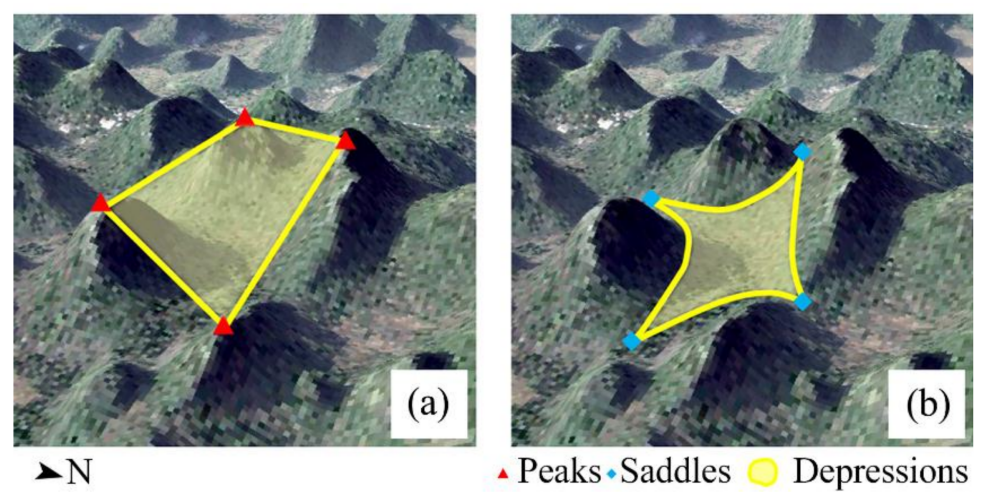

Figure 1. Two views regarding extent of depressions in Fengcong areas: (a) the entire range surrounded by peaks and $(\mathbf{b})$ the concave part under the saddles.

Second, an entire Fengcong karst area is regarded as a typical combination of convex peaks or positive terrains and concave depressions or negative terrains with a coupling relationship of positive-negative terrain. The interface between the pinnacles or positive terrain and depression or negative terrain comprise saddles. The boundary of this type of depression (Figure 1b) was defined by field investigation and visual inspection in previous studies [30-33]. However, these techniques are time consuming and difficult to conduct for complex terrain, thus leading to the slow progress in the boundary extraction of karst depressions in many previous studies.

Only a few of these studies have explored the fundamental issue of the accurate boundaries of depressions in Fengcong karst depression areas. The specific location of the depressions should be determined in a follow-up study. The combination of multiple saddles constitutes a hydro-geodynamic interface with different properties $[34,35]$. Above this interface should be the pinnacles which belong to positive terrains, while below this interface should be depressions which belong to negative terrains. A saddle is a key geomorphological feature of Fengcong depressions and genetically related to the local spatial geology and climate [30]. This feature is the low point between two hills along a ridge line 
and characterizes the intersection of the ridges and valleys in a Fengcong depression terrain. A saddle appears convex in one direction and concave in another in digital elevation models (DEMs).

On the basis of the idea that the Fengcong karst depression is the concave part of a saddle, this work presents a convenient method of extracting the depression from Fengcong karst areas from DEM data. With Guilin (China) as the case study area, the spatial locations of the saddles in a Fengcong depression are extracted through the digital terrain analysis method from DEMs. The surface of the saddles, which represents the interface between depressions and pinnacles in Fengcong area, is established using spatial interpolation method. The distribution of the depressions in the Fengcong area is then obtained by overlay calculation. Finally, we analyze the morphological characteristics and discuss the developmental stages of the Fengcong depressions in Guilin.

\section{Case Area and Method}

\subsection{Case Area}

The study area in Guilin, Guangxi Province $\left(110.25^{\circ}-110.52^{\circ}\right.$ E, $\left.24.88^{\circ}-25.10^{\circ} \mathrm{N}\right)$, covers a total area of approximately $74.1 \mathrm{~km}^{2}$, and has more than 180 depressions. The area is known as one of the most beautiful karst landforms in the world [5]; its spectacular karst landforms developed mainly from Devonian and Carboniferous limestone [36]. Figure 2 shows that the study area is a typical place where Fengcong landforms develop. The region is in the Lijiang River Basin and is a composite N-S trending synclinal basin surrounded by the Haiyang Mountain in the northeast and Jiaqiao Ling Mountain in the southwest. The area is an excellent hydrogeological unit; its north, east, and west parts have high elevation, whereas the central part has low elevation. Pinnacles in the area have a general height of approximately $200 \mathrm{~m}$, and most of them are cone-shaped. The Lijiang River flows through the eastern side of the study area and serves as the major drainage system. The vicinity of the Lijiang River has small streams and lakes, which may influence the morphology of the depressions $[3,37,38]$.
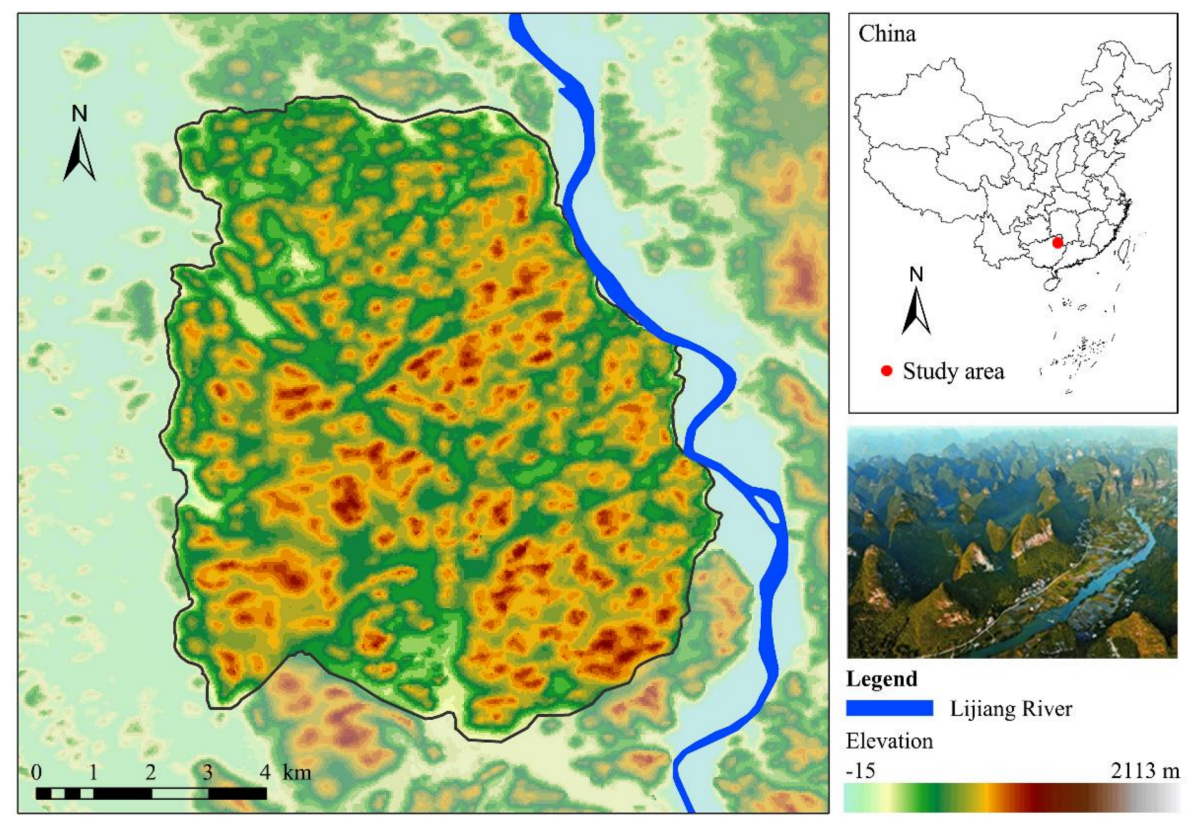

Figure 2. Study area in Lijiang River in Guilin, Guangxi Province, China.

The data source in the case study area is a DEM derived from the National Administration of Surveying, Mapping and Geoinformation of China. The ground sampling distance (or cell size) of the original DEMs is 0.5 arc-second. After preprocessing, the cell size of the DEM has been resampled to $15 \mathrm{~m}$. 


\subsection{Methods}

A Fengcong depression is a karst terrain that shows a clear distinction between positive and negative terrain. Each Fengcong depression is composed of upward pinnacles (positive terrain) and downward depressions (negative terrain). The conversion interface between the positive and negative terrain comprises saddles. On a karst terrain, saddles are also the intersections of ridge and valley lines. We extract all the saddles in the study area using their spatial location feature. Finally, according to the spatial location and elevation data of the saddles, an appropriate spatial interpolation method is adopted to identify the trend surface of the saddles in the whole area and draw the boundaries of the depression in this region on the basis of this trend surface.

\subsubsection{Extraction Saddles from Intersection of Ridge and Valley Lines}

In hydrophysical process research, the extraction of ridges and valleys should be the division of watersheds and the extraction of catchments, respectively. In recent years, numerous methods have been applied for the automatic extraction of ridge and valley lines using GIS [39-42]. In this work, the commonly used confluence accumulation method is utilized to extract the ridge and valley lines. In hydrological analysis, the ridge lines are also the surface watershed lines, which are the origins of water flow, that is, the point with zero confluence accumulation. Meanwhile, the points with zero flow accumulation are derived by surface runoff simulation calculation. The valley lines can be extracted through the reversed terrain, which is extracted by subtracting the original DEM value from a value larger than it. This process transforms the valley lines in the original DEM into the ridge lines in the reversed terrain. The method for extracting the ridge lines can be used again in the reversed terrain to extract the valley lines.

In this algorithm, the calculated water flow accumulation is related to the absolute elevation but not to the relative elevation. The ridge area (high relative elevation) and the micro topography in the gully (low relative elevation) are extracted as features. Therefore, the convex points with relatively high elevation at the bottom of the slope can be extracted as the ridge points. These erroneous feature points must be addressed considering the morphological characteristics of the saddles.

Although saddles are at the intersections of ridge and valley lines, not all such intersections constitute saddles. In Fengcong karst depression areas, saddles are generally on small flat surfaces. The slope value is small, but the slope rate of change is generally high.

Therefore, the selection of saddles is mainly based on the slope change rate, which represents the second order derivative of ground elevations. Usually, the slope change rate increases near saddles. Therefore, an appropriate threshold of slope change rate should be selected, and the intersection of ridge and valley lines with increased slope change rates should be identified. In addition, the mutation points in the microscope convex terrain also have a large slope and small change in slope. These points should be eliminated, thereby leaving the real positions of the saddles.

\subsubsection{Fengcong Depression Extraction Analysis}

In Fengcong depression areas, the elevation of each saddle varies. The boundary and shape of the depressions also differ. Therefore, this interface is not a simple uniform plane. According to the actual spatial distribution of saddles in Fengcong depressions, a suitable spatial interpolation method is used to find the interface, and then the spatial distribution of depressions can be derived. In DEM-based terrain analysis, spatial interpolation is often used to analyze the spatial trend of discrete spatial data and determine the distribution of certain morphological features. The prediction capability, preconditions, complexity, output precision, and processing speed of various interpolation models all differ. Various interpolations applied to the same situation will yield remarkably different results. In this study, the following method is used to interpolate the saddles in the study area according to the elevations and spatial distribution of saddles, considering the applicable conditions of diverse spatial interpolation methods. 
The interpolation method used in this research is based on the ANUDEM program, which was developed by Michael Hutchinson [43-45]. This program is often used to interpolate a hydrologically correct raster surface from point, line, and polygon data. The interpolation process uses commonly used input data types and the known features of the elevation surface. This method utilizes iterative finite difference interpolation, which is optimized to achieve computational efficiency in implementing local interpolation methods without sacrificing the surface continuity of global interpolation methods. This technique is classified as a discretized thin-plate spline method [46]. The roughness penalty coefficient is modified. After the DEM is fitted, the terrain structure becomes continuous, and the surface morphology is accurately represented. Actual terrain mutation, such as rivers, ridges, and cliffs, can be restored. With the application of specific constraints, the discrete terrain points are interpolated into raster elevation planes, and the continuity and accuracy of terrain structure are guaranteed. The trend surface is generated on the basis of the extracted saddles by this method. Finally, the depressions in the Fengcong can be obtained by subtracting the trend surface from the original terrain data.

\section{Results}

\subsection{Extracted Saddles}

According to the $15 \mathrm{~m}$ DEM data of the Yangshuo test area in Guilin (China), the pinnacles and depressions are well-developed and the surface has noticeable water diversion lines. The location of each saddle can be accurately found in the test area through the relationship between ridge and valley lines. The hydrological analysis method, combined with positive and negative terrain theory, is used to extract the ridge and valley lines in the study area. The results are shown in Figure 3.

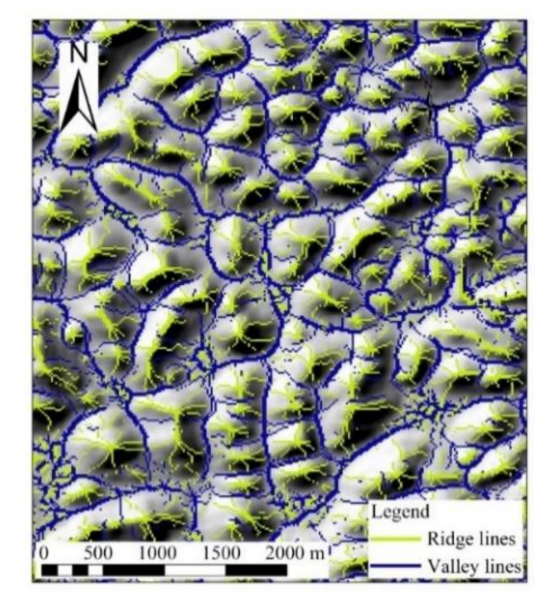

Figure 3. Ridge and valley lines in Fengcong depression area.

Figure 3 shows that the ridges and valleys intersect on saddles. However, several intersections are found between the bottom of the slope and near the edge of the study area. According to topographic maps and high-resolution remote sensing images of the area, these intersections are all located in places where the morphology of the surface changes quickly. The two main kinds of extracted points are the actual saddle points and the small mutation points on the ground. According to the actual terrain, the saddle is at the lower part between the two peaks and is the highest place on the valley line between two depressions. The location of each saddle generally has a gentle slope, but its surroundings have a relatively large slope. In the study area, saddles are always located where the slope is small and the slope changing rate is high. Small mutation points are always located where the slope is large but the slope change rate is low (Figure 4). On the basis of this characteristic, we can accurately identify the saddles by considering the slope and its change rate. 

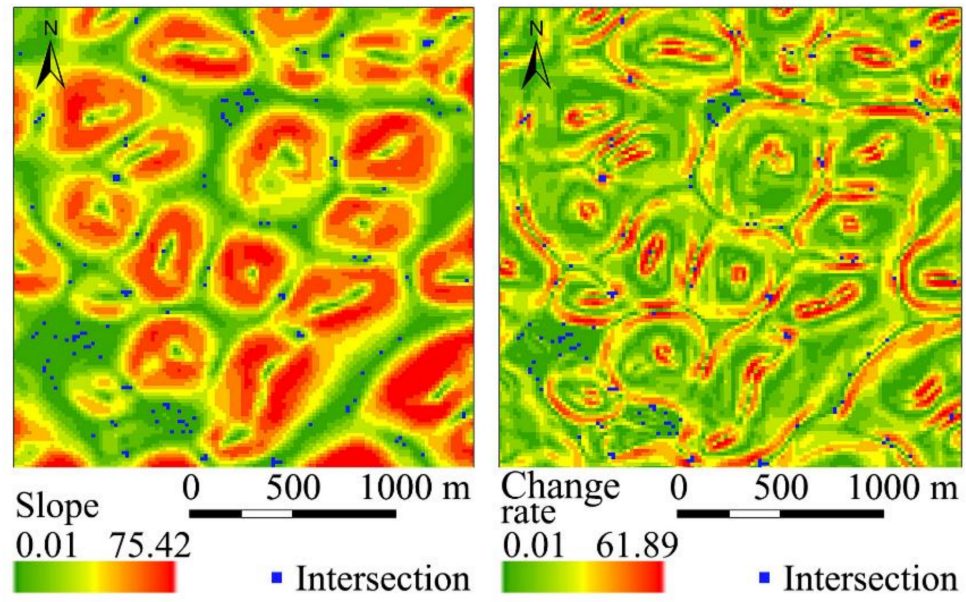

Figure 4. Location of intersection points of slope and its change rate.

According to the extracted results, most of the false saddle points (Figure 4) in the low-lying area are removed and nearly all the saddles in the study area are extracted. (Table 1 and Figure 5). The extracted results are compared with topographic maps for accurate analysis. From the study area, 708 saddles are extracted, 28 of which are missing and 42 are errors. The overall accuracy is $90.11 \%$. Certain details can be lost during the process of DEM production and preprocessing due to the complexity of the terrain in the sample area. Therefore, several saddle points are not extracted in this research. In addition, several saddle areas are remarkably large and thus result in erroneously extracted saddle points.

Table 1. Statistics on number and elevation of extracted saddle points.

\begin{tabular}{ccccc}
\hline Total & Missing & False & True & Accuracy \\
\hline 708 & 28 & 42 & 638 & $90.11 \%$ \\
Maximum elevation & Minimum elevation & Average elevation & Median elevation & Standard deviation \\
$513.8 \mathrm{~m}$ & $187.1 \mathrm{~m}$ & $368 \mathrm{~m}$ & $369.5 \mathrm{~m}$ & $59.8 \mathrm{~m}$ \\
\hline
\end{tabular}
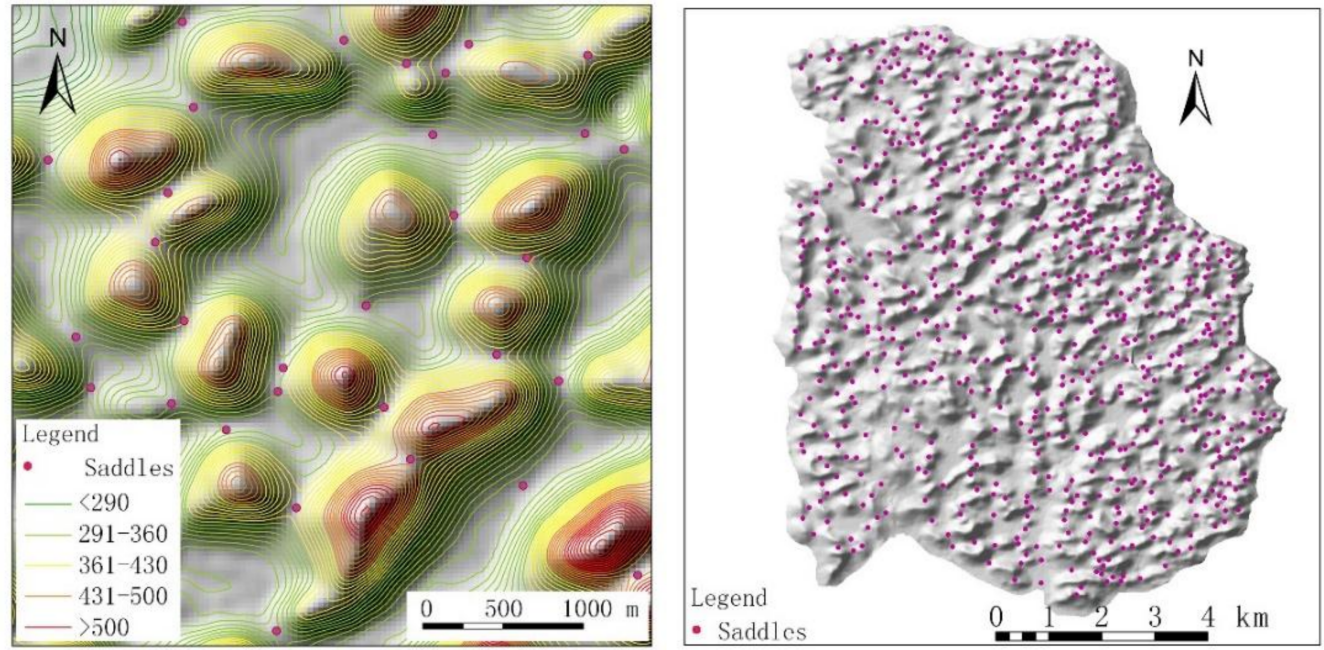

Figure 5. Extracted saddle points.

In this research, a total of 708 saddles are extracted from the study area. Most of the saddles are located between elevations of $280 \mathrm{~m}$ and $460 \mathrm{~m}$ (Figure 6). Regarding spatial distribution, saddles 
with high elevations are mainly distributed along the southern and eastern parts of the Lijiang River. Saddles with low elevations are distributed across the area in the central flat around the trench parts (see Figure 2). From the distribution of the pinnacles and the depressions, the north of the study area is a complete Fengcong area; its interior is well-distributed, and the pinnacles have similar heights. The rock formation in this area is slightly folded or approximately horizontal. Pinnacle groups are distributed in patches or clumps and show sinkholes, funnels, depressions, and other forms of closed negative terrain. The southern part of the study area is a set of complete limestone rocks. The degree of corrosion is low, the differences between the pinnacles of distinction are not noticeable, and the depressions are not significantly distributed. Therefore, the saddles positions are relatively high.

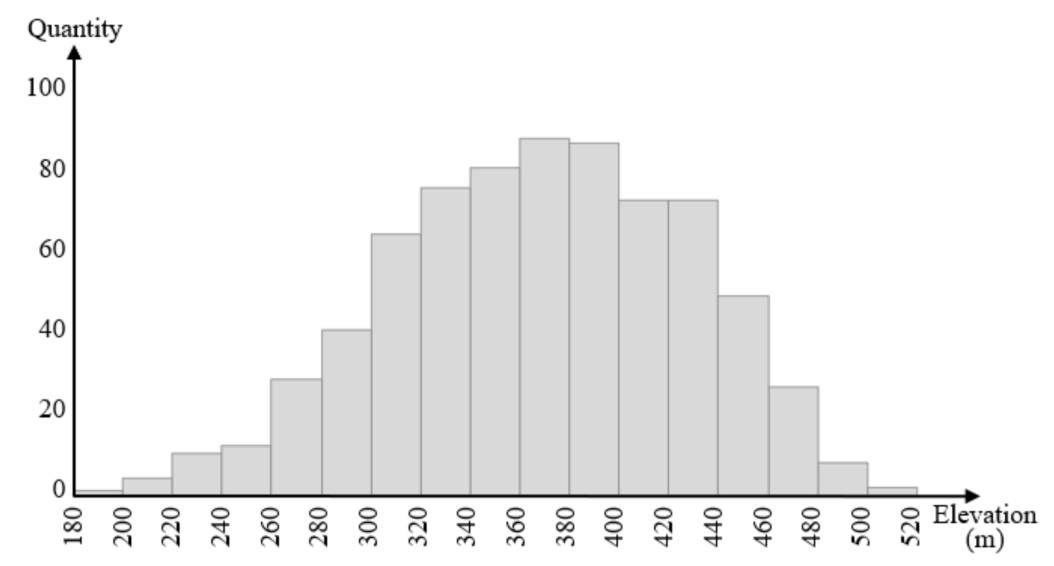

Figure 6. Histogram of elevations of saddles.

\subsection{Fengcong Depressions}

The extracted saddle points have a wide range of elevations according to the data. The points are disorganized and irregular. The accuracy of the data, the smoothness of the surface of the space, and the spatial meaning of the saddle point are considered, and an algebraic method is used to obtain the Fengcong depressions. A total of 188 surface depressions are extracted. The minimum and maximum areas are 0.01 and $0.98 \mathrm{~km}^{2}$, respectively; the average area is $0.14 \mathrm{~km}^{2}$; the density of the polygonal depression is $2.5 \mathrm{~km}^{2}$; and the total depression area in the study region is $25.6 \mathrm{~km}^{2}$, which accounts for approximately $1 / 3$ of the study area. The morphological characteristics, such as area, elevation, depth, length, width, and shape of the 188 depressions extracted from this study area are statistically analyzed (Table 2 and Figure 7).

Table 2. Morphological characteristics of depressions in study area.

\begin{tabular}{ccccc}
\hline Depressions & Maximum & Minimum & Mean & Standard Deviation \\
\hline Area $\left(\mathrm{km}^{2}\right)$ & 0.98 & 0.01 & 0.14 & 0.16 \\
Surface elevation $(\mathrm{m})$ & 463 & 215 & 340 & 51 \\
Bottom elevation $(\mathrm{m})$ & 450 & 192 & 316 & 54 \\
Depth (m) & 114 & 3 & 42 & 28 \\
Length/Width & 3.37 & 1.05 & 1.69 & 0.43 \\
\hline
\end{tabular}




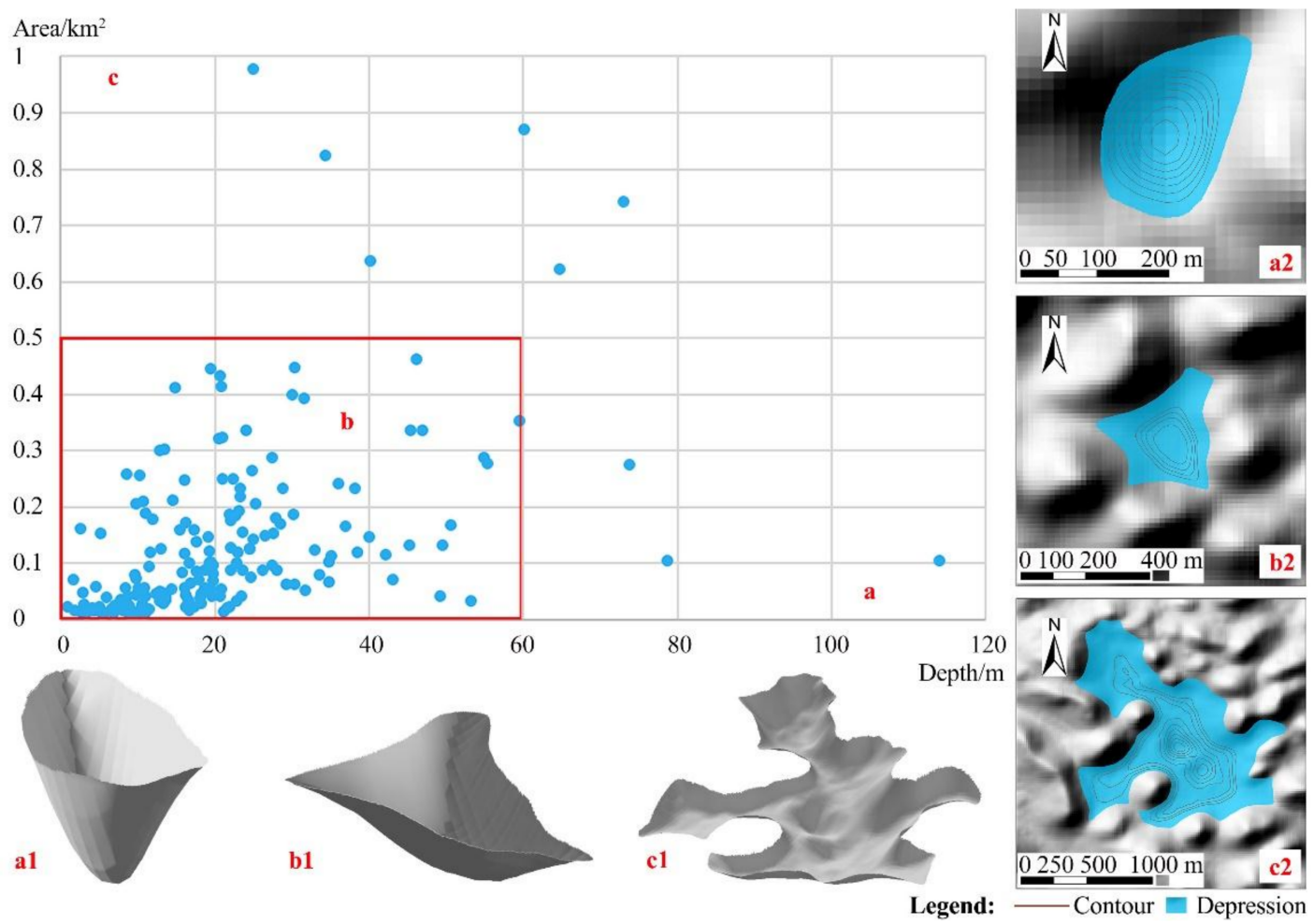

Figure 7. Plane and side morphological characteristics of depressions in study area.

The depressions in this area are distributed over a wide range, except the southwest part, where nearly all areas have depression distribution. The depression area is the smallest throughout the region along the Lijiang River, gradually increases toward the central area, and becomes small again in the eastern area. The area of the depression is closely related to the elevation of the saddle points as it gradually decreases with the increase in the elevation of the saddle points. This finding shows that the formation of large depressions seems rather difficult, especially in the high Fengcong area. In the middle of the area, large depressions are often easily formed due to the cumulative effect of the catchment.

A further analysis of the area, depth, and morphological characteristics of the depression area shows that most of the depression area is remarkably stable. A total of $94 \%$ of the depth is less than $60 \mathrm{~m}$, and the area is less than $0.5 \mathrm{~km}^{2}$ (Figure $7 \mathrm{~b}$ ). According to the geological structure conditions, the stable area of the depressions in this area measures approximately $0.5 \mathrm{~km}^{2}$. The depressions are mainly formed by the erosion of the surface precipitation. Each depression is closed and independent of one another, and each depression constitutes a small catchment. An analysis of the plane and side views of most of the depressions in the sample area (Figure $7(\mathrm{~b} 1, \mathrm{~b} 2)$ ) shows that the shapes of the depressions are noticeably controlled by the surrounding hills. The depressions show irregular polygons, and the bottom of the depressions have small flat surfaces.

The study area features several large depressions. An analysis of their plane and side views (Figure 7c) shows that they comprise multiple small depressions. The combined depressions have different degrees of development; some are conical at the bottom, and some are flat. In addition, the study area has small and deep depressions (Figure 7a). The contour lines of these depressions are dense. A side view shows that these contour lines are conical or approximately tubular. In the early development stage of the Fengcong depression in Guilin, the depressions were inverted conical. Over time, most of the depressions stopped developing downward and began developing laterally, gradually forming shallow dish-like shapes and flat bottoms. Several individual depressions were eroded by flowing water on the sloped surface and swallowed the surrounding small depressions to 
form nested depressions. Meanwhile, some depressions were affected by the fissure in the bedrock and developed downward to form sinkholes.

\section{Discussion}

\subsection{Comparison with Hydrologic Analysis Methods}

The most commonly used method for extracting karst depressions in the past is based on sink filling in hydrological analysis [47]. Sinks in a surface raster are usually filled before DEMs are used in hydrological modeling [48,49]. These sinks are filled to remove small imperfections in the data, thereby allowing the filled elevation value to be the same as the surroundings. Conversely, the sinks can be extracted by a comparison of the processed and unprocessed DEMs. Therefore, sink fillings are commonly used in extracting sinkholes or depressions [12,19,50-52]. The method identifies a depression by judging the elevation relationship between a certain point and the surrounding pixel points. The method considers only the difference between the point data and the surrounding data elevation values and does not considerably focus on the actual surface morphology reflected by the data. The result is as follows (Figure 8 and Table 3).
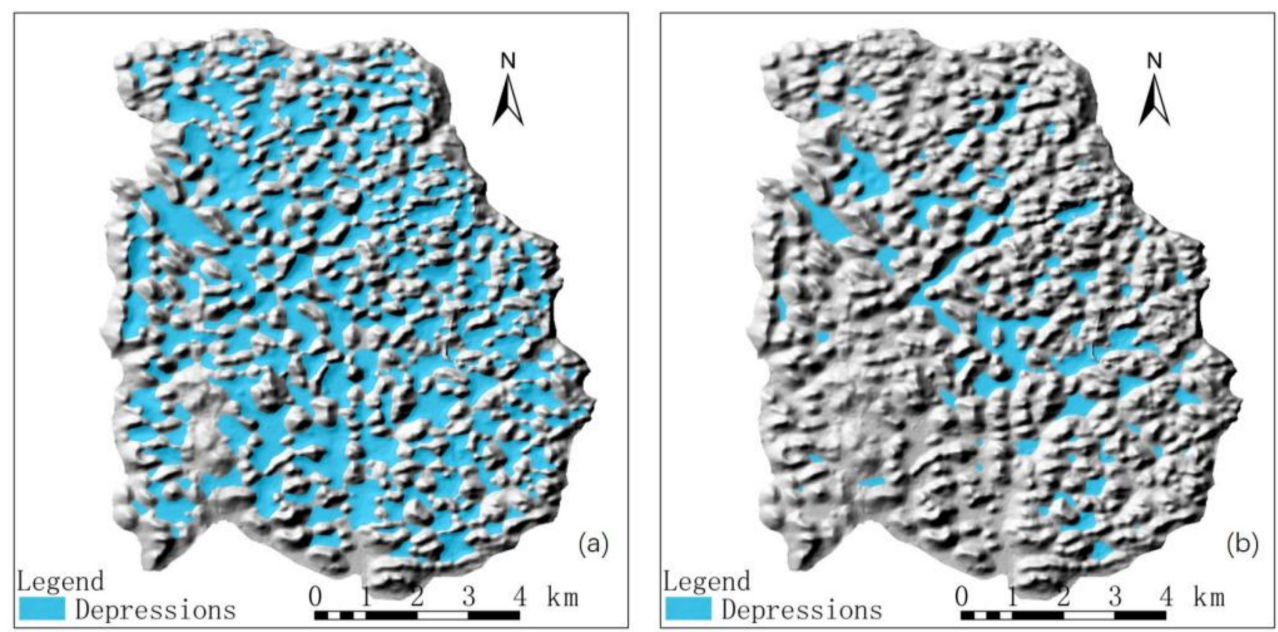

Figure 8. Depressions extracted using (a) saddle position method and (b) hydrologic analysis method.

Table 3. Morphological characteristics of depressions using hydrologic method and saddle position method.

\begin{tabular}{cccccc}
\hline \multirow{2}{*}{ Method } & \multirow{2}{*}{ Number } & \multicolumn{5}{c}{ Area $\mathbf{( k m}^{\mathbf{2}} \mathbf{c}$} \\
\cline { 3 - 6 } & & Maximum & Minimum & Mean & Total Area \\
\hline hydrologic method & 82 & 0.84 & 0.00015 & 0.074 & 6.08 \\
saddle position method & 188 & 0.98 & 0.01 & 0.14 & 25.6 \\
\hline
\end{tabular}

Eighty-two surface depressions are extracted using the hydrologic analysis method. The maximum area is $0.84 \mathrm{~km}^{2}$, the average area is $0.074 \mathrm{~km}^{2}$, and the total depression area in the study region is $6.08 \mathrm{~km}^{2}$. Most of the depressions are in the middle of the area. No depressions exist at the high altitudes around the region. Of these depressions, seven areas are below $0.001 \mathrm{~km}^{2}$ and the minimum area is only $0.00015 \mathrm{~km}^{2}$. Apparently, these extractions are merely small pits on the ground and not depressions. The filled depressions and the depressions in the karst peaks are two completely different concepts, and the results are substantially different. The depressions obtained by this method are mainly in the areas that have noticeable topographical changes in the central part, and those in certain small peaks and valleys are ignored. 
The results extracted by the filling method in traditional hydrological analysis and our method are compared. The traditional hydrological analysis method does not consider the karst terrain characteristics, extracts several false depressions, and misses many real depressions. From the extracted results, the method used in this work is significantly better than the traditional method. The depressions between pinnacles of different elevations (including depressions, karst basins, sinkholes, and dolines) are all fully extracted.

\subsection{Implication of Landform Development}

Natural depressions are fully developed in karst areas and considered the index landform of karstification [53]. According to Smith and Atkinson [54], morphometric studies "not only provide an adequate description of surface morphology and allow meaningful comparison between areas, but ... they may give an insight into the evolution of forms within individual regions" [31]. The morphology of the depressions can reflect the stage of development. Most of the depressions in Guilin are small. The number of depressions decreases significantly with the increasing area (Figure 9). Thus, the development rates of most of the depressions in the area are consistent. According to the theory of the geomorphic cycle, the depressions in the karst area are mainly formed by the erosion caused by precipitation. Polygonal depressions are isolated depressions close to one another, with each being a separate catchment.
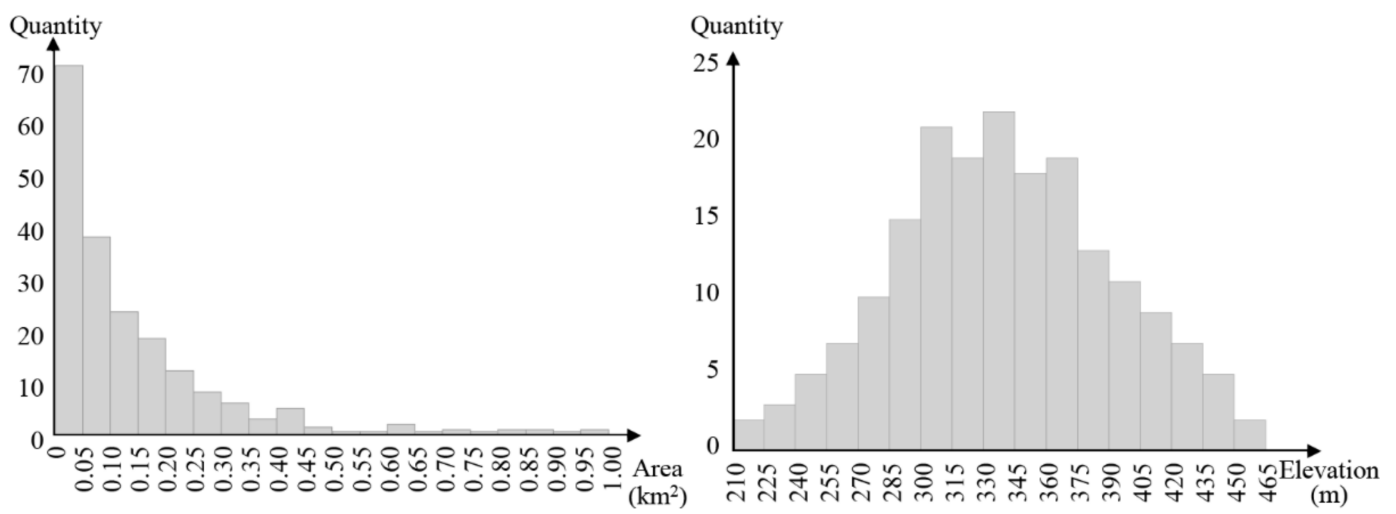

Figure 9. Area histogram and surface elevation histogram of depressions.

At the early stage of development, the depressions are deepened vertically and the area is continuously expanding. At this stage, small depressions constitute most of area, medium depressions are few, and no large combined depressions are present. The bottoms of the depressions are relatively stable. Joints or fractures are few, and the depressions are not considerably disturbed by the surroundings being in a stable and natural state of development. With the evolution of polygonal depressions, the depression areas gradually increase and deepen. When the area and depth of the depressions reach a certain size, the horizontal and vertical development rates noticeably slow down and gradually stabilize. At this point, the development of the depressions enters maturity, and many medium-sized depressions appear. Small depressions are reduced, and large nested depressions begin to appear. With the continuous effect of precipitation and erosion by water flow in the depression and of the bottom carbonate, the bottoms of several depressions begin to flatten and laterally swallow the surrounding small depressions to form a large combined depression. Other depressions follow the joints and fissures of carbonate rocks to form sinkholes or collapse. In this period, several large combined depressions and remarkably small-deep depressions appear. The number and morphological characteristics of the Fengcong depressions in Guilin show that the development of the depressions is generally in the growth stage and the depressions are exhibiting slow development. 


\section{Conclusions}

In this work, a method that is based on topographic saddle points and uses DEM data to extract depressions in Fengcong areas is explored for the first time. By analyzing the concept of depression in Fengcong areas, this work concludes that saddles are the true demarcation points between karst pinnacles and depressions. This finding is often neglected. The exact positions of saddles are extracted by using DEM data combined with digital terrain analysis. The interpolation method is used to generate the interface between pinnacles and depressions. An analysis of the area, depth, and shape of these depressions shows that the depressions in Guilin are generally in a period of growth and development may still continue.

This method provides a rudimentary basis for follow-up studies on the quantitative expression of Fengcong karst depressions, which may present a new idea for the study of such depressions. This method is more automated than previous manual surveys and interprets remote sensing images, which are suitable especially for the extraction of Fengcong depressions in complex terrain. The extracted surface between pinnacles and depressions is also an essential interface for studies about karst hydrodynamic geomorphology.

However, the extraction of complex nesting karst depressions in the study area is not sufficiently accurate due to the limitations of DEM data quality and analysis methods. Difficulties exist in areas where Fenglin and Fengcong areas coexist. Although the method of dividing depression surfaces considers the characteristics of the depressions, it still does not perfectly solve the problem of saddle connection, thus resulting in the extraction of small false depressions. These issues still need to be solved in subsequent research.

Acknowledgments: This research has been supported by the National Natural Science Foundation of China (No. 41701449, No. 41601411, No. 41671389, No. 41571398, and No. 41771423), Nanhu Scholars Program for Young Scholars of XYNU. We are grateful to the members of the DEM research group for their stirring discussions and the reviewers for their helpful comments on this manuscript. This support is gratefully acknowledged.

Author Contributions: Xianwu Yang proposed the method, performed analysis and wrote the paper. Liyang Xiong conceived the study, designed the experiments. Xin Meng collected and processed the data. Guoan Tang conceptualization, and review \& editing of this paper.

Conflicts of Interest: The authors declare no conflict of interest.

\section{References}

1. Zhu, X. Discussions on fenglin karst in China. Carsologica Sin. 2009, 28, 155-168.

2. Zhu, D. Evolution of peak cluster-depression in Guilin area and morphometric measurement. Carsologica Sin. 1982, 2, 127-134.

3. Yuan, D. About Fenglin karst. Geol. Guangxi. 1984, 1, 79-84.

4. Sweeting, M.M. Karst in China: Its Geomorphology and Environment; Springer: Berlin, Germany, 1995.

5. Tang, T.; Day, M.J. Field survey and analysis of hillslopes on tower karst in Guilin, southern China. Earth Surface Process. Landf. 2000, 25, 1221-1235. [CrossRef]

6. Zhou, C. A Dictionary of Geomorphology; China WaterPower Press: Beijing, China, 2006.

7. Waltham, T. Fengcong, fenglin, cone karst and tower karst. Cave Karst Sci. 2008, 35, 77-88.

8. Day, M. The morphology and hydrology of some Jamaican karst depressions. Earth Surface Process. Landf. 1976, 1, 111-129. [CrossRef]

9. Gutiérrez, F.; Cooper, A.H.; Johnson, K.S. Identification, prediction, and mitigation of sinkhole hazards in evaporite karst areas. Environ. Geol. 2008, 53, 1007-1022. [CrossRef]

10. Gutiérrez, F.; Galve, J.P.; Lucha, P.; Castañeda, C.; Bonachea, J.; Guerrero, J. Integrating geomorphological mapping, trenching, InSAR and GPR for the identification and characterization of sinkholes: A review and application in the mantled evaporite karst of the Ebro Valley (NE Spain). Geomorphology. 2011, 134, 144-156. [CrossRef]

11. Tüfekçi, K.; Şener, M. Evaluating of karstification in the Menteşe Region of southwest Turkey with GIS and remote sensing applications. Zeitschrift Für Geomorphologie 2007, 51, 45-61. [CrossRef] 
12. Obu, J.; Podobnikar, T. Algorithm for karst depression recognition using digital terrain models. Geodetski Vestnik. 2013, 57, 260-270. [CrossRef]

13. Tang, G. Progress of DEM and digital terrain analysis in China. Acta Geogr. Sin. 2014, 69, 1305-1325.

14. Kobal, M.; Bertoncelj, I.; Pirotti, F.; Kutnar, L. Lidar Processing for Defining Sinkhole Characteristics under Dense Forest Cover: A Case Study in the Dinaric Mountains. ISPRS-International Archives of the Photogrammetry. Remote Sens. Spat. Inf. Sci. 2014, XL-7, 113-118.

15. Narayana, A.C.; Yadava, M.G.; Dar, F.A.; Ramesh, R. The Spectacular Belum and Borra Caves of Eastern India. In Landscapes and Landforms of India; Springer: Dordrecht, The Netherlands, 2014.

16. Liang, F.; Xu, B. Discrimination of tower-, cockpit-, and non-karst landforms in Guilin, southern china, based on morphometric characteristics. Geomorphology 2014, 204, 42-48. [CrossRef]

17. Liang, F.; Du, Y.; Ge, Y.; Li, C. A quantitative morphometric comparison of cockpit and doline karst landforms. J. Geogr. Sci. 2014, 24, 1069-1082. [CrossRef]

18. Wu, Q.; Deng, C.; Chen, Z. Automated delineation of karst sinkholes from LiDAR-derived digital elevation models. Geomorphology 2016, 266, 1-10. [CrossRef]

19. Zhu, J.; Pierskalla, W.P. Applying a weighted random forests method to extract karst sinkholes from LiDAR data. J. Hydrol. 2016, 533, 343-352. [CrossRef]

20. Song, L.; Deng, Z. Fractal and geometry of karst depressions in South China. Geogr. Res. 1995, 14, 8-16.

21. Wang, D.; Xu, M.; Qi, J.; Zang, Q. Analysis on morphologic features of the peak-cluster depression in Qiubei, Southeast Yunnan. Carsologica Sin. 2010, 29, 239-245.

22. $\mathrm{Xu}, \mathrm{M}$. Study on morphological characteristics of karst landform based on the fractal theory. J. Chengdu Univ. Technol. 2011, 38, 328-333.

23. Yi, Z.; Tang, G.; Xin, Y.; Xiao, C.; Zhang, Y.; Luo, M. Positive and negative terrains on northern Shaanxi Loess Plateau. J. Geogr. Sci. 2010, 20, 64-76.

24. Xiong, L.; Tang, G.; Yan, S.; Zhu, S.; Sun, Y. Landform-oriented flow-routing algorithm for the dual-structure loess terrain based on digital elevation models. Hydrol. Process. 2013, 28, 1756-1766. [CrossRef]

25. Zhu, X. Guilin Karst; Shanghai Scientific and Technical Publishers: Shanghai, China, 1988.

26. Xiong, K. Hydrodynamic genetics of cone karst and tower karst-With special reference to the middle Guizhou. Carsologica Sin. 1994, 3, 237-246.

27. Yang, M.; Liang, H. The processes of evolution dynamic of cone karst and the exploitation of the water resource. Carsologica Sin. 2000, 1, 44-51.

28. Yuan, D. Modern karstification; Science Press: Beijing, China, 2016.

29. Yang, M.; Zhang, Y.; Smart, P.; Waltham, T. Karst geomorphology of western Guizhou, China. Carsologica Sin. 1987, 6, 345-352.

30. Jiang, Z. An analysis on formation of the karst Fengcong depressions in China. Carsologica Sin. 1996, 15, 83-90.

31. Lyew-Ayee, P.; Viles, H.A.; Tucker, G.E. The use of GIS-based digital morphometric techniques in the study of cockpit karst. Earth Surface Process. Landf. 2007, 32, 165-179. [CrossRef]

32. Rahimi, M.; Alexander, E. Locating Sinkholes in Lidar Coverage of a Glacio-Fluvial Karst, Winona County, MN; University of South Florida: Tampa, FL, USA, 2013.

33. Zhu, J.; Taylor, T.P.; Currens, J.C.; Crawford, M.M. Improved karst sinkhole mapping in Kentucky using LIDAR techniques: A pilot study in Floyds Fork watershed. J. Cave Karst Stud. 2014, 76, 207-216. [CrossRef]

34. Yang, M.; He, C. Developmental Characteristics of Cone-shaped Karst in China. In Proceedings of Danxia Mountain; The Geographical Society of China: Garmin Taiwan, 2004.

35. Thrailkill, J. Karst Geomorphology and Hydrology. Derek Ford, Paul Williams Geomorphology and Hydrology of Karst Terrains. William B. White. J. Geol. 1991, 98, 797-798.

36. Deng, Z.; Lin, Y.; Zhang, M.; Liu, G.; Wei, Z. Karst and Geological Structure in Guilin; Chongqing Publishing House: Chongqing, China, 1988. (In Chinese)

37. Yuan, D.; Drogue, C.; Aide, D.; Wenke, L.; Wutian, C.; Bidaux, P.; Razack, M. Hydrology of the karst aquifer at the experimental site of Guilin in southern China. J. Hydrol. 1990, 115, 285-296.

38. Day, M.J. The role of valley systems in the evolution of tropical karstlands. In Evolution of Karst: From Prekarst to Cessation; Gabrovsek, F., Ed.; Zalozba ZRC: Ljublana, Slovenia, 2002; pp. 235-241.

39. Aumann, G.; Ebner, H.; Tang, L. Automatic derivation of skeleton lines from digitized contours. ISPRS J. Photogramm. Remote Sens. 1991, 46, 259-268. [CrossRef] 
40. Dayasagar, B.S.; Murthy, M.B.R.; Baburao, C.; Baldev, R. Morphological approach to extract ridge and valley connectivity networks from Digital Elevation Models. Int. J. Remote Sens. 2003, 24, 573-581.

41. Koka, S.; Anada, K.; Nomaki, K.; Sugita, K.; Tsuchida, K.; Yaku, T. Ridge detection with the steepest ascent method. Procedia Comput. Sci. 2011, 4, 216-221. [CrossRef]

42. Lv, G.; Xiong, L.; Chen, M.; Tang, G.; Sheng, Y.; Liu, X.; Song, Z.; Lu, Y.; Yu, Z.; Zhang, K.; et al. Chinese progress in geomorphometry. J. Geogr. Sci. 2017, 27, 1389-1412. [CrossRef]

43. Hutchinson, M.F.; Dowling, T.I. A continental hydrological assessment of a new grid-based digital elevation model of Australia. Hydrol. Process. 1991, 5, 45-58. [CrossRef]

44. Hutchinson, M.F. Optimising the degree of data smoothing for locally adpative fintie element bivariate smoothing splines. Anziam J. 2000, 42, C774. [CrossRef]

45. Hutchinson, M.F.; Xu, T.; Stein, J.A. Recent Progress in the ANUDEM Elevation Gridding Procedure. In Proceedings of the Geomorphometry 2011, Redlands, CA, USA, 7-9 September 2011.

46. Wahba, G. Spline Models for Observational Data; Society for industrial and applied mathematics: Philadelphia, PA, USA, 1990.

47. Tarboton, D.G.; Bras, R.L.; Rodriguez-Iturbe, I. On the extraction of channel networks from digital elevation data. Hydrol. Process. 1991, 5, 81-100. [CrossRef]

48. Wilson, J.P.; Gallant, J.C.; Hutchinson, M.F. Future directions for terrain analysis. In Terrain Analysis: Principles and Applications; John Wiley: Hoboken, NJ, USA, 2000.

49. Burrough, P.A.; McDonnell, R.A.; Lloyd, C.D. Principles of Geographical Information Systems; Oxford University Press: Oxford, UK, 2015.

50. Mukherjee, A. GIS analysis of sinkhole distribution in Nixa, Missouri. In Proceedings of the GSA Annual Meeting in Charlotte, Seattle, WA, USA, 22-25 October 2012.

51. Carvalho, O.A.D.; Guimarães, R.F.; Montgomery, D.R.; Gillespie, A.R.; Gomes, R.A.T.; Martins, É.D.S.; Silva, N.C. Karst depression detection using ASTER, ALOS/PRISM and SRTM-Derived digital elevation models in the Bambuí group, Brazil. Remote Sens. 2013, 6, 330-351. [CrossRef]

52. Miao, X.; Qiu, X.; Wu, S.S.; Luo, J.; Gouzie, D.R.; Xie, H. Developing efficient procedures for automated sinkhole extraction from Lidar DEMs. Photogramm. Eng. Remote Sens. 2013, 79, 545-554. [CrossRef]

53. Ford, D.; Williams, P.W. Karst Hydrogeology and Geomorphology; Wiley: Hoboken, NJ, USA, 2007.

54. Smith, D.I. Process, Land-forms and Climate in Limestone Regions. In Geomorphology and Climate; Wiley: London, UK, 1976. 